\title{
Surgical Experiences from the Boer War
}

\author{
Commentary \\ PJ Parker
}

The author states that after every war 'the views hitherto held by military surgeons will necessarily be subject to modification'. At the beginning of the 20th century and only eleven years before the 'war to end all wars' this was never truer. He remarks that the '...experience gained by surgeons, practising their profession under the difficult circumstances of active service' must be published in order to pass this wisdom on to the next generation. Even semi-anecdotal articles of this type can go some way to preserving our institutional memory. As well as being entertaining, they also provide valuable historical lessons to those of us that are left - but only of course if we read them!

\section{The Author}

William Flack Stevenson was born in Dublin in 1844. He joined the Army Medical Services in 1866 and was the Professor of Military Surgery from 1892 to 1895 . He held the rank of Surgeon General whilst Principal Medical Officer, Lines of Communication in South Africa from 1899 to 1900 . He was made CB(Military) in 1900 and KHS on retirement in 1905. He authored the third edition of 'Wounds in War' which was published in 1910. In the November of 1914 at the age of 70, he was recalled to duty in the 'Great War'. WF Stevenson died in 1922 in Bournemouth.

\section{Historical Notes}

The Boer War took place just over one hundred years ago. It was precipitated by the invasion of the Natal and the Cape Colonies by the Boer peoples in 1899. This was in response to British fortune hunters pouring into, and staking claims within, this diamond and mineral-rich area. It was mainly a guerrilla war but there were some famous fixed battles such as the siege of Ladysmith and the capture of Bloemfontein. Kitchener was seen as the mastermind behind the British victory. However, certain of his methods came under later criticism. He moved slowly, burned farms and settlements, and placed the Boer civilian population into ill-equipped 'concentration camps'. These had a high death rate, largely due to a lack of medical services. The Treaty of Pretoria ended the war in 1902.

The Chilean war refers to the "War of the Pacific' which was fought from 1879 to 1883. Chile and Bolivia (and later Peru) came into dispute over guano deposits in the Atacama
Desert: the nitrate rich guano being a raw material for fertilizers and explosives. In 1879 Chilean troops landed at Antofagasta and occupied the then Bolivian coastline and the southern provinces of Peru. Fighting continued until 1883. Bolivia lost its Pacific coastline and the Chileans did not sign a formal peace treaty with Peru until 1929.

\section{Bullet Development}

In the early 19th century most small-arms weapons were muzzle loading smooth-bore muskets which fired soft lead balls. After 1850 these were displaced by a smaller calibre, higher velocity projectile designed by a Frenchman, Claude-Etienne Minié. These Minié bullets were specifically designed, with a hollow base and soft conoidal head, to deform on impact. During the American Civil War of 1861 to 1865 , surgeons noted 'the amount of devitalized tissue surrounding the bone wounds...resembled the effects of an explosion' and that 'pulpification of soft parts was noted at some distance from the tract of the [Minié] bullet...the wound of exit was irregular and measured as much as three to four inches in its longest diameter'.

After the Civil War, bullets were jacketed in that the lead core was now surrounded by a steel or copper jacket. This allowed an increase in both muzzle velocity and range. Surgeons (reporting from the 1904-5 RussoJapanese and 1898 Spanish-American Wars) found that these jacketed bullets with their higher muzzle velocities were often not as destructive as the slower softer bullets. Injuries to non-vital areas were less severe and this 'humane bullet' was not liked by the rank-and-file infantry. At the military arsenal in Dum-Dum, near Calcutta, British troops filed the ends off their bullets to expose the soft lead core. These 'Dumdums' as they were then known, caused unusually devastating wounds. The Third Declaration of the Hague Convention of 1899 banned the use of deforming bullets in wars between the signatories. All military bullets were to have 'full metal jackets' for the sake of humanity!

\section{Lethality}

Stevenson's conjecture that the change in the ratio of dead to wounded during this period was due to improved surgery and not the new projectile is, I believe, valid. The low $20 \%$ suppuration rate may also have been helped by the 'climate, sunshine and dry, pure 
air'. This happy circumstance was not to last. Alexander Fleming's 'heavily manured soils of Flanders' where wound infection was the norm and one in ten wounds developed gas gangrene was only a decade away. Stevenson also noted the use of a dilute sewage that passed as water and the lack of fuel that prevented its boiling as an area that certainly required improvement. This want of clean water is a recurring theme in every war. In the recent conflict in Afghanistan in 2001, British Special Forces Surgical teams had to use bottled mineral water as the irrigation fluid during surgery for limb gunshot wounds.

Limb wound mortality was high in the Boer war. As in the American Civil War, the mortality from femoral gunshot wounds was greater than $50 \%$. This did not change until 1916 with the introduction of the Thomas Splint (first described by Owen Thomas in 1875). By Vietnam the mortality was only $1.4 \%$. The high fatality rate reported during the 600 mile rail transport of these unsplinted compound femoral fractures in the pre-antibiotic Boer war is therefore understandable. Stevenson searches for a solution.

The ratio of killed to wounded (or uncorrected lethality) in the Boer war was 0.28 for officers and 0.32 for soldiers. This is a very reasonable figure. During the Normandy landings of June 1944, small arms fire caused $31 \%$ of the total British casualties with a lethality of 0.39 . The cumulative figures for US troops in World War II was 0.38. Fragment wounds had a lethality of 0.21 . In Northern Ireland our own experience was a 0.37 lethality for highvelocity wounds and just 0.08 for lowvelocity ones. This ratio of just over one killed for three wounded needs to be remembered by the military planners of today. There are no clean conflicts.

\section{Wound Distribution}

The distribution of these missile wounds remains unchanged. Stevenson noted a $60 \%$ rate of extremity wounds in the Boer War. In WWII $65 \%$ of all missile wounds were in the extremities. In Korea it was $67 \%$ and in Vietnam $66 \%$. Abdominal wounds were by comparison; $8 \%$ in WWII, $7 \%$ in Korea and $5 \%$ in Vietnam. The need for orthopaedic surgeons in wartime remains extant. However, the British Army currently has only one uniformed orthopaedic surgeon for every 24,000 serving men and women - five in total. In the American Civil War, the Union Forces had 11,000 surgeons, the Confederacy 3,000. Finally, the treatment of gunshot injuries to the head - proactive fracture elevation, removal of the depressed and loose bone does not seem to have changed much in a century. A mortality rate of greater than $50 \%$ for high velocity injuries was observed.

\section{Summary}

We must continue to publish our accounts of conflict surgery, good or bad. This will help to maintain our institutional memory and serve as lessons for the next generation of surgeons.

\section{Acknowledgments}

I would like to thank Capt (Retd) P Starling RAMC, Curator AMS Historical Museum, Keogh Barracks, Aldershot who assisted me with biographical research for this paper.

\section{Bibliography}

Emergency War Surgery, NATO Handbook (First Revision) 1975. United States Government Printing Office, USA.

Textbook of Military Medicine. Part 1, Volume 5 1990. Conventional Warfare Ballistic, Blast and Burn Injuries. Office of the Surgeon General, Department of the Army, USA.

Civil War Battlefield Medicine. http://www.aretesurf.com/cwmedicine.

Encarta World English Dictionary 1999.

Bloomsbury, London.

Atlas of World History 1999, Dorling Kindersley, London. 


\title{
RAMC Journal 1903 Vol 1. No.2. 83-91 Original Communications. NOTES ON SURGICAL EXPERIENCES OF THE BOER WAR
}

\author{
By Surg.-Gen. W.F. Stevenson, C.b. \\ Royal Army Medical Corps.
}

When the surgical experiences of the Spanish-American and Boer Wars are available in detailed histories of the events of these campaigns, and when they have been considered with the attention they will deserve, it is probable, or indeed certain, that the views hitherto held by military surgeons on various matters as regards diagnosis, treatment and prognosis of gunshot wounds will necessarily be subjected to considerable modification. These were the first campaigns in which the armies on both sides were armed with modern weapons and in which the surgeons, practising their profession under the difficult circumstances of active service, published their methods of treatment, and the results obtained from them. In the Chilian War of 1893 both sides used small-bore rifles; but from a surgical point of view that war was wasted, because little or nothing was done to bring before our profession either the effect of the small projectiles on human tissues, or the results of the surgical treatment employed for the cure of the wounds inflicted by them. But already something has been done in this connection in America, by the reports of the SurgeonGeneral of the United States Army for the years 1899, 1900, 1901 and 1902, and a vast amount of material recording our own experiences in South Africa is available at the War Office, which is now being worked into convenient shape for easy reference.

That the opinion and practice of military surgeons will undergo great change in consequence and the experiences of the two late wars will depend on two things - the use of a hard-mantled bullet of small diameter and great energy, and the employment, so far as is possible in the field, of modern methods of surgical procedure. The damage done to the various structures of the body by the old and by the new bullet differs very greatly, the former, no doubt, producing more extensive injuries in certain situations and under certain conditions than the latter, and requiring more often the performance of radical operations for their cure. But I must confess that I am not one of those who look upon the small-bore rifle bullet as a "humane" and "merciful" one, terms frequently applied to it by surgeons in writing of it's effects. With reference to the injuries it produces in certain situations joints, the skull, the abdomen - perhaps it deserves to be held in better repute than did the older and larger rifle bullets. But this character of the modern projectile is conveyed to one's mind by considering particular cases; it is neither humane nor merciful if we look at it from a more general point of view. Ascertain, for instance, what proportion of men hit by it in an engagement are killed outright on the field, and compare this with what happened in former wars. The lethal effects of small-arm fire has varied enormously in the wars of the last two hundred years, and these variations depend for the most part on the kind of operations being carried out, and on the nature of the ground which they covered. At Blenheim, in 1704 , the proportion was one man killed to 1.3 wounded - nearly as many killed as wounded. At Borny and Vionville, the French lost only 1 to 7 , almost the two extremes for all wars; while the available statistics for the whole two hundred years up to date show the average to be 1 killed to 4 wounded. In the late Spanish-American war, where smallbore rifles were used on both sides, the ratio of killed to wounded was 1 to 5.7 as an average for the three years of the war, and 1 to 3.1 for the year 1900. In the Boer War the similar ratio was 1 to 3.5 amongst officers, and 1 to 3.9 amongst N.C.O.'s and men; or, taking the average for the two late wars, the small-bore bullet has killed outright in the field one man to every 4.7 it merely wounded; and further, in both wars, indeed, in all wars since the formation of special units for the purpose of picking up the wounded and carrying them to the field hospitals, only to die in a few hours, and thus diminish the apparent lethal effects of the missiles which wounded them. Looked at in this way, there is, no doubt, a little in favour of the modern bullet's "humanity," but it is only a very little.

That the percentage of deaths among the wounded in war hospitals is much less than it used to be has also been placed to the credit of the new projectile, but undeservedly so, as I believe. That the endeavour to approach, as nearly as may be in a campaign, to the modern methods of surgical treatment employed at home is largely accountable for the diminished death-rates amongst the wounded I feel convinced, and that opinion is supported by the evidence of the reports of their experiences both by civil surgeons and by officers of the Royal Army Medical Corps. That the best possible has not yet been obtained from antiseptic methods in war must be admitted; but that the attempts made in South africa towards that desired 
end were productive of excellent results is certain. A certain percentage - perhaps 20 per cent. - of cases suppurated; but one of the features of the surgery of the war was the comparative absence of surgical infective disease. Some few surgeons who were in South Africa hold but a poor opinion of the effects of antiseptic treatment in the Boer War, ascribing the good results which were obtained to the climate, the sunshine, and the dry and pure air, \&c. In the absence of the conditions they were accustomed to at home, those of civil hospitals at their best in these matters, they were unable to give any credit to first field dressings and to antiseptic materials in the treatment of the wounds. But on the other hand, there is much evidence directly opposed to this. I have had facilities for reading reports by a large number of surgeons who were at the war, and who, taking quite the opposite view, attributed the failure of antiseptic treatment to prevent suppuration when it occurred to the pest of flies, the high winds, and an atmosphere laden with dust, which permeated everything, do what they would to keep it out; in fact, they attribute everything to the climate and conditions under which they worked and which they were powerless to ameliorate. The condition of all others which was most inimical to antiseptic procedures in South Africa was the want of water suitable for making antiseptic lotions.

Unless antiseptic cleansing of the wound and of the skin around it is possible from the first, suppuration is certain to occur; but the difficulties in obtaining water for preparing solutions at the front, at the bearer companies' dressing stations and at the field hospitals were often insuperable. Except in the larger towns - and often in them also - all the water to be obtained between Modder River Station and Koomati Poort was muddy, much of it being best described as dilute sewage. Muddy water will not pass through a Berkefeld filter, and boiling it was impossible in the vast majority of cases because fuel was not available. Under these very adverse circumstances it was not to be expected that anything approaching ideal asepticism could be secured.

Nevertheless, all the trouble and expense paid to reach that ideal in south Africa were not merely so much wasted energy, for the mortality of the wounded in the hospitals was less than that of any previous war, except the Spanish-American. In the Civil War in America the death-rate amongst the wounded who reached the hospitals for treatment was 14.3 per cent., The vast majority of the deaths being due to infective disease resulting from suppuration. In the Boer War 8.7 per cent. of the wounded died, and in the Spanish-American War, 6 per cent. ; that is, that at an average for the two late wars, the deaths of the wounded were reduced by 50 per cent. as compared with the earlier war. Surely this was worth trying for, though it is not as good as might be expected under more favourable conditions.

Some surgeons believe that the low deathrate of the wounded in the Boer War was due to the trivial nature of the injuries produced by the small-bore bullets. No doubt they are trivial when unimportant soft parts only are traversed by them; but in other cases the term cannot properly be applied to them. Statistics for the Boer War are not yet ready, but it is permissible to argue from the deathrates afforded by injuries in the various regions of the body in the Spanish-American War to the death-rates which will probably be found to be correct for the Boer War. The death-rates of gunshots of the skull, of the spine and of the abdomen in the SpanishAmerican War were not reduced, as compared with those for the Civil War, in nearly the same proportion as were those of the extremities. Therefore, if the general percentage of deaths is reduced, it must be in consequence of better results in injuries of the chest and of the extremities. Penetrating gunshots of the chest gave a mortality of 27.2 per cent., as compared with the former rate of over 50 per cent. This no doubt is largely due to the less severe injuries produced in the lungs by small projectiles, and antiseptics cannot claim much of the credit in this connection. But when the extremities are injured - and over 60 per cent. of all wounds seen in war are of the extremities - and when the large bones are fractured, the term "trivial" certainly does not describe the wounds correctly. When one examines a large number of cases or event in any connection, one is sure to find a considerable number of exceptions to the general rule, and so it was in South Africa. A considerable number of cases of clean perforations of long bones, or otherwise exceptionally slight fractures were observed; but any one who has studied the large number of skiagrams of fractures of the diaphyses of long bones which have been sent home from South Africa will, I feel sure, be more inclined to apply the term "terrific" rather than "trivial" to the injuries produced in these situations. These fractures were of the utmost severity as regards comminution, with fragments displaced up and down the limb to long distances, as well as forwards through the exit wound, lacerating the muscles, and frequently the vessels and nerves as well, the giving rise to such serious complications as traumatic aneurisms and paralysis of the parts below. In many cases the site of the fracture was completely cleared of bone fragments, thus leaving a separation between the ends of the broken bones of many inches in length. The figures given in the accompanying plate are reproductions of skiagrams of cases met with in South Africa, and these could be added to in large numbers from the collection in the Royal Army Medical College; They can 
hardly be considered trivial injuries. Usually cases of this kind were produced at fairly short ranges - up to 600 yards, but at medium and long ranges, comminuted fractures of great extent were likewise experienced; indeed, it is well recognised that fractures produced at extreme ranges - over 1,700 yards - are often more severe than those caused at from 1,200 to 1,500 yards, in consequence of the bullet wobbling round a point just behind it's shoulder.

In former wars cases of this kind were treated by primary amputation, because of the practically certain death which resulted from suppuration and septicaemia if treated conservatively. In the Civil War of America, " 44.4 per cent. of gunshot fractures of the shaft of the femur were promptly amputated." In the Spanish-American War, 7.3 per cent. of similar cases were so treated; while in the Boer War, if we put the ratio of primary amputations for fractures of all long bones at 4 per cent., we shall probably have overstated it. What, then, was the cause of these better results in the late wars? Was it not the use of antiseptic methods, imperfect though they necessarily were, rather than that the injuries were trivial.

During the American Civil War conservative treatment of femur cases gave a 
death-rate of 49.9 per cent. ; in the SpanishAmerican War it was 13.1 per cent. ; and unless the fractures sustained by American soldiers in Cuba were different to those seen among the British in South Africa, this lesser fatality must have been due, not to the insignificance of the injuries, but to the use of modern surgical procedures in their treatment.

One of the greatest predisposing causes of suppuration in fracture cases is the early transport of the wounded towards the base, so often rendered unavoidable by the necessity of evacuating field hospitals to enable them to advance with brigades or columns. It does not much matter whether the transport is by wagon or by wellequipped hospital trains, nearly all the cases suppurate, especially those of the lower extremity. We had a valuable object-lesson in this respect among the wounded from Belmont, Modder River and Magersfontein, who were sent down to Cape Town by hospital train, most of them arriving in a septic condition, many of them dying, and many requiring secondary amputations. Whereas later experience showed - though it hardly required demonstration - that if cases of this kind could be transferred into stationary field hospitals near the field of battle, and treated there for two or three weeks, these untoward results were not produced.

Formerly it was a generally held opinion that if cases of severe gunshot fractures of the lower extremity had to be moved towards the base soon after the receipt of their wounds, primary amputation, although not actually indicated from a surgical point of view, gave the patients a better chance of life, and certainly saved them much pain and suffering. mr. Makins points out in his "Surgical Experiences," that in South Africa amputation cases bore transport badly; he "saw few in which flaps did not slough, or worse consequences ensue." This no doubt, is perfectly correct, but what both he and I saw of thigh and leg cases in Wynberg hospital after a 600 mile journey in a hospital train led me to believe that when treated conservatively they bore it still worse.

Gunshot fractures of the skull were a peculiarly interesting class of case in South Africa, and instructive as well. Practically all the cases wounded at short range - under, say, 150 yards - died immediately, or within a few hours; but the degree of injury to the brain decreased so rapidly with increase of range, that many extraordinary cases were seen in the hospitals, and some very marvellous survivals, not to say recoveries, were experienced. Otis, the writer of the surgical history of the American Civil War, mentions that fourteen of the cases of complete perforation of the skull lived to be invalided from the Service; that one of them was alive nine years later, but none of them were able to earn a livelihood. In the Boer War, complete perforation of the skull without death supervening was quite common. Many cases of the passing of a bullet through both frontal lobes without producing any symptoms were seen; and others in various situations, producing symptoms from complete hemiplegia and epileptiform convulsions to mere paresis of certain muscles, recovered sufficiently to be sent to England. Some, even of the more severe cases, apparently recovered completely, in that no symptoms remained when they left South Africa; but, judging from previous experience, the prognosis must be bad for a considerable time perhaps years. One case I know developed epilepsy and insanity a year after his return in apparently perfect health, but has again recovered.

The experiences of this war have emphasised one point which was already pretty generally admitted - that all gunshot injuries require operation for the elevation and removal of the depressed and loose bone; that fewer mistakes will be made if the rule be followed that, in all cases in which there is evidence, no matter how slight, of contact of a bullet with the vault of the skull, an operation must be performed, rather than the practice that operations should only be undertaken in the presence of signs of brain injury. The evidence to this effect was beyond all doubt. Cases in apparently hopeless condition commenced to improve from within a day to a week after operation, and eventually were sent home more or less recovered. The use of the trephine is not required in the great majority of operations for gunshot injury to the skull, as there are usually apertures of sufficient size to admit the point of a Hoffman's gouge forceps, or of Sir Victor Horsley's similar instrument. Moreover, the openings in the bone can be enlarged to any extent with these. Gutter fractures should be trephined at both ends, and usually the whole of the floor of the gutter composed of the comminuted and often depressed inner table requires removal. Civil Surgeon L.G. Irvine, who has written an excellent report of his experiences in South Africa, and published an article on head injuries in the Lancet of October 25, 1902 , is of opinion that what he terms as "superficial perforating" fractures - those in which there are two apertures in the skull, but close together, so that the track of the bullet lies close below the inner table - are a more fatal class of injury than the "deep perforating" fractures, in which the track of the bullet is lower down, and is the arc of a larger chord of the vault. Fractures in which the base, and more especially the posterior and middle fossae, are implicated are the gravest of all; indeed, they practically all die, whether inflicted at long or short ranges. 
One point with regard to gunshot fractures of the skull must impress one on reading the notes of cases in the late Boer War: the large number of recoveries which have occurred, notwithstanding the onset of suppuration in the wounds. It has always been recognised that the usual cause of death is those cases of gunshot of the skull which reach the field hospitals for treatment is septic meningitis, the result of infection of the wounds; and further, I believe I am correct in saying that when these wounds become infected, very little expectation of recovery was held. But in the South African War, experience showed that too unfavourable a prognosis need not be made under the circumstances referred to, for a very large number of such cases recovered without any untoward events complicating the convalescence. When, of course, the suppuration runs to the extent of hernia, or abscess of the brain, then, indeed, the case assumes a different complexion. What the death-rate of gunshot fractures of the skull in the Boer War will amount to is at present impossible even to guess; but although I have said a good deal as to recoveries in these cases, that being the interesting matter in connection with them, it is probable, judging from the statistics of the Spanish-American War, that they will still prove to have been a very fatal class of injury. The use of small-bore bullets and antiseptics in the Spanish-American War only reduced the deaths in penetrating gunshots of the skull to 54.4 per cent., as compared with 59 per cent. for the Civil War of the Rebellion.

I shall bring this paper, already perhaps too long, to a close by short notes of two cases of gunshot fracture of the skull. In one case a Mauser bullet traversed the skull horizontally through both occipital lobes. The man was unconscious for a short time after the receipt of the injury, and on recovering from this condition found that he was totally blind. The blindness continued absolute for six hours, and then commenced to disappear. Vision improved fairly rapidly for a week, and then much more slowly. At the end of six weeks he could get about unassisted; but vision was still very defective, and was not improving. But the curious part of this case was that no other symptom except the one mentioned, cerebral or otherwise, presented itself previous to his being sent home.

The other was quite a surgical curiosity. The man was transferred to a general hospital six days after the receipt of a bulletwound of the head. A shell had burst close to him, and he believed a small piece of stone had hit him on the forehead, but this proved to be incorrect. He described himself on admission as feeling "quite well." There was a small dry scab over the middle of the frontal bone, and no other wound. On touching the scab with an aseptic probe, the instrument passed into the skull. Three days later the temperature went up, cerebral symptoms commenced, and the man became very restless, almost violent. A flap was turned up, including the situation of the wound, and a small circular aperture was found in the bone; many loose spicules of bone were removed. This operation removed all the symptoms immediately; but at the end of the week the same symptoms again appeared, and a fluctuating swelling formed two inches above the right auditory meatus. This was incised, giving exit to a large quantity of pus and a fracture of the skull was discovered. A trephine was applied and some loose pieces of bone removed. It was then that the pus came from an abscess of the brain three inches deep, and passed out through the broken bone. This was irrigated and drained, the man making an uninterrupted recovery. A skiagram showed a Mauser bullet at the base of the brain! 